\title{
Doenças em eucaliptos destinados à produção de energia na região Sul do Brasil
}

\author{
Celso Garcia Auer ${ }^{1}$, Álvaro Figueredo dos Santos ${ }^{1}$ \\ ${ }^{1}$ Embrapa Florestas, Estrada da Ribeira, Km 111, CP 319, CEP 83411-000, Colombo, PR, Brasil
}

"Autor correspondente:

auer@cnpf.embrapa.br

Termos para indexação:

Eucalyptus

Patógenos

Proteção florestal

Index terms:

Eucalyptus

Pathogens

Forest protection
Resumo - O eucalipto é o segundo gênero florestal mais plantado na região Sul do Brasil, para a produção de celulose, papel e energia. A expansão contínua dos plantios comerciais de eucalipto na região Sul do Brasil tem levado ao aumento na incidência e severidade de doenças. O presente trabalho discute a ocorrência e a distribuição de doenças do eucalipto nessa região, as espécies suscetíveis e os agentes causais. Estratégias de controle como o mapeamento de áreas de risco, o uso de material genético resistente e o controle químico são medidas adequadas para minimizar os impactos negativos na produção de madeira para energia. As doenças, em especial a ferrugem do eucalipto, que reduzem a produtividade e a qualidade da madeira foram consideradas as mais importantes e que devem ser controladas.
Histórico do artigo: Recebido em 10 jun 2011

Aprovado em 19 dez 2011

Publicado em 28 mes 2011

doi: $10.4336 / 2011 . p f b .31 .68 .373$

\section{Impacts of diseases on eucalypts used for energy forests in southern region of Brazil}

\begin{abstract}
Eucalypts are the second forest species most planted in Southern Brazil, for production of cellulose, paper and energy. The continued expansion of commercial plantations in southern Brazil region has led to an increase on incidence and severity of diseases. The present work discusses the occurrence and distribution of diseases associated to this region, susceptible species, and causal agents. Strategies for control such as mapping of risk areas, use of resistant genetic material and chemical control are adequate measures to minimize negative impacts on wood production for energy. Diseases, as eucalypt rust, that reduce the productivity and wood quality were considered the most important and must be controlled.
\end{abstract}

\section{Introdução}

Na última década, a expansão da eucaliptocultura tem ressaltado um aumento no registro de doenças em viveiros e nas plantações florestais, nos estados da região Sul do Brasil. Algumas doenças sem expressão econômica já eram conhecidas como o cancro e a ferrugem do eucalipto desde a década de 1980 (Krugner, 1980; Ferreira, 1989), contudo, estas e novas doenças surgiram e causam preocupação pelos danos potenciais às plantações florestais (Krugner \& Auer, 2005). A preocupação deve-se ao fato de espécies plantadas para a produção de energia como Eucalyptus benthamii, E. dunnii, E. viminalis (plantados em localidades mais frias) e E. grandis, E. cloeziana, E. urophylla, E. camaldulensis e Corymbia maculata (plantados em localidades mais quentes) e seus híbridos possam ser severamente atacados, devido à falta de material genético resistente para plantios comerciais em pequenas e médias propriedades rurais, empresariais e cooperativas. 
Neste trabalho são apresentadas as informações referentes às doenças que ocorrem na cultura do eucalipto, sua distribuição na região Sul do Brasil e discutem-se os riscos à produção de florestas energéticas. Estes dados foram obtidos a partir de diagnoses realizadas pelo Laboratório de Patologia Florestal da Embrapa Florestas em materiais doentes oriundos de viveiros, plantios comerciais e áreas experimentais. Os registros iniciaram-se em 1989 e foram publicados periodicamente (Maschio et al., 1996; Santos et al., 2001; Auer \& Santos, 2009a). Algumas das informações mais recentes contemplam compilações de dados feitos por Alfenas et al. (2009) e estudos com patógenos exóticos registrados na região Sul (Pérez et al., 2009).

\section{Principais doenças}

As enfermidades reportadas na região Sul podem ser agrupadas em: viveiros (Tabela 1) e plantios (Tabela 2). As doenças apresentadas na Tabela 1 acarretam impactos negativos somente na fase de produção de mudas, enquanto que na Tabela 2 são apresentadas as doenças que podem comprometer a produção e a qualidade da madeira.

Algumas destas doenças se destacam como potencialmente importantes para a eucaliptocultura na região Sul do Brasil e são apresentadas a seguir:

1) Cancro do eucalipto - o agente causal é o fungo Crysoporthe cubensis Gryzenh. \& M. J. Wingf. Esta doença foi registrada, nas espécies $E$. grandis. E. oreades e $E$. viminalis, por Auer (1996). Das espécies que podem ser plantadas na região Sul, E. benthamii, E. dunnii e E. urophylla também podem ser atacadas (Ferreira, 1989), contudo, não existem registros de ocorrência.

O patógeno causa mortalidade de árvores jovens, a partir dos seis meses de idade, podendo se estender até o segundo ano. Posteriormente, a doença se manifesta na forma de lesões na casca, em várias porções do tronco, com a presença de calo cicatricial. Pode, ainda, ocorrer a redução na brotação de touças e a quebra de fustes de árvores doentes ou mortas, pela ação de vento forte (Ferreira, 1989; Krugner \& Auer, 2005). Em decorrência destes sintomas, pode ser observada a redução na produção e na qualidade energética da madeira afetada pela doença (madeira com menor poder calorífico) decorrente da ação de microrganismos apodrecedores e insetos broqueadores.

2) Ferrugem - o agente causal é o fungo Puccinia psidii Winter. A doença foi registrada somente em $E$. grandis e E. dunnii (Auer et al., 2010). Os principais danos da ferrugem são: a redução da área fotossintética e o impedimento do crescimento nos dois primeiros anos de idade das árvores altamente suscetíveis (Ferreira, 1989). Após esta idade, a doença não causa danos. O impacto pode ser verificado na redução da produtividade da floresta nos primeiros anos de crescimento, com consequente queda no seu volume final.

A ferrugem do eucalipto tem despertado grande preocupação no setor florestal, por ser considerada a principal doença deste gênero. Algumas universidades brasileiras, empresas privadas e a Embrapa Florestas têm direcionado suas pesquisas para estudos de aspectos epidemiológicos e desenvolvimento de estratégias para o seu controle.

O fungo $P$. psidii apresenta grande número de hospedeiros nativos (mirtáceas) e encontra-se na maioria das plantações de eucalipto (Auer et al., 2010). A fonte de inóculo natural advindo das matas nativas garante a ocorrência contínua da doença, tornando o controle mais difícil de ser atingido. Tais hospedeiros do patógeno causador da ferrugem não podem ser eliminados, uma vez que fazem parte da estrutura da floresta nativa e as mirtáceas são fontes de alimento para a fauna silvestre e comunidades humanas.

A principal estratégia de controle da ferrugem envolve a seleção e uso de material genético resistente (Alfenas et al., 2009). Outra estratégia de controle comentada por Auer et al. (2010) é avaliar as áreas de ocorrência de $P$. psidii para conhecer sua distribuição na região Sul do Brasil (Figura 1), para fazer o zoneamento das áreas favoráveis à doença visando ao plantio de clones resistentes (Masson, 2009). Recentemente, o controle químico vem sendo trabalhado experimentalmente com estudos sobre produtos, doses e intervalos de aplicação para em curto prazo dispondo-se de fungicidas registrados no Ministério da Agricultura, Pecuária e Abastecimento que possam ser utilizados em seu controle (Santos \& Auer, 2011). 
Tabela 1. Doenças e agentes causais registrados em viveiros de eucaliptos na região Sul do Brasil.

\begin{tabular}{|c|c|c|c|c|}
\hline Doença & Agente causal & Hospedeiro & UF & Referência \\
\hline Tombamento de mudas & Botrytis cinerea & Eucalyptus dunnii & PR & Maschio et al. (1996) \\
\hline Tombamento de mudas & Cylindrocladium candelabrum & Eucalyptus grandis, E. dunnii & $\mathrm{PR}, \mathrm{SC}$ & Maschio et al. (1996) \\
\hline Tombamento de mudas & Fusarium oxysporum & Eucalyptus grandis, E. viminalis & PR, SC & Maschio et al. (1996) \\
\hline Tombamento de mudas & Rhizoctonia solani & Eucalyptus dunnii & PR & Maschio et al. (1996) \\
\hline Mofo cinzento & Botrytis cinerea & $\begin{array}{l}\text { Eucalyptus dunnii, E. benthamii, E. viminalis, } \\
\text { E. grandis }\end{array}$ & $\mathrm{PR}, \mathrm{SC}$ & Maschio et al. (1996), \\
\hline Podridão de estacas & Cylindrocladium candelabrum & Eucalyptus dunnii $x$ benthamii & PR & Auer \& Santos (2009a) \\
\hline Podridão de estacas & Rhizoctonia sp. & Eucalyptus dunnii $x$ benthamii & PR & Auer \& Santos (2009a) \\
\hline Oídio & Oidium eucalypti & $\begin{array}{l}\text { Eucalyptus alba, E. badjensis, E. benthamii, } \\
\text { E. camaldulensis, E. cloeziana, E. deanei, } \\
\text { E. dunnii, E. grandis, E. microcoris, E. nitens, } \\
\text { E. paniculata, E. pellita, E. pilularis, } \\
\text { E. resinifera, E. robusta, E. saligna, } \\
\text { E. tereticornis, E. urophylla, E. viminalis. } \\
\text { Corymbia citriodora, C. maculata, C. } \\
\text { torelliana. }\end{array}$ & PR & Auer \& Santos (2009a) \\
\hline Ferrugem & Puccinia psidii & Eucalyptus grandis & $\begin{array}{l}\text { PR, SC, } \\
\text { RS }\end{array}$ & Auer et al. (2010) \\
\hline Mancha foliar & Cylindrocladium candelabrum & Eucalyptus viminalis, E. grandis, E. dunnii & $\mathrm{PR}, \mathrm{SC}$ & Auer \& Santos (2009a) \\
\hline
\end{tabular}

Tabela 2. Doenças e agentes causais registrados em plantações de eucaliptos na região Sul do Brasil.

\begin{tabular}{|c|c|c|c|c|}
\hline Doença & Agente causal & Hospedeiro & UF & Referência \\
\hline Oídio & Oidium eucalypti & Corymbia citriodora & PR & Maschio et al. (1996) \\
\hline Mancha foliar & Pilidiella eucalyptorum & $\begin{array}{l}\text { Eucalyptus robusta, E. urophylla, Eucalyptus } \\
\text { grandis } x \text { urophylla (E. urograndis) }\end{array}$ & $\mathrm{SC}$ & Auer \& Santos (2009a) \\
\hline Mancha foliar & Kirramyces epicoccoides & $\begin{array}{l}\text { Eucalyptus grandis, E. benthamii, } \\
\text { E. urograndis }\end{array}$ & $\begin{array}{l}\text { PR, SC, } \\
\quad \text { RS }\end{array}$ & $\begin{array}{l}\text { Maschio et al. (1996), } \\
\text { Auer \& Santos } \\
(2009 a)\end{array}$ \\
\hline Mancha foliar & Cylindrocladium candelabrum & $\begin{array}{l}\text { Eucalyptus viminalis, E. grandis, E. } \\
\text { urophylla, E. dunnii }\end{array}$ & $\mathrm{PR}, \mathrm{SC}$ & Auer \& Santos (2009a) \\
\hline Mancha foliar & $\begin{array}{l}\text { Mycosphaerella spp.; } \\
\text { Teratosphaeria } \text { spp. }\end{array}$ & $\begin{array}{l}\text { Eucalyptus viminalis, E. dunnii, E. saligna, } \\
\text { E. globulus }\end{array}$ & $\begin{array}{l}\text { PR, SC, } \\
\quad \text { RS }\end{array}$ & $\begin{array}{l}\text { Maschio et al. (1996), } \\
\text { Pérez et al. (2009) }\end{array}$ \\
\hline Mancha foliar & Harknessia sp. & Eucalyptus viminalis, E. grandis, E. dunnii & PR & Maschio et al. (1996) \\
\hline $\begin{array}{l}\text { Mancha foliar } \\
\text { bacteriana }\end{array}$ & Xanthomonas axonopodis & E. urograndis & $\mathrm{PR}, \mathrm{SC}$ & Auer \& Santos (2009a) \\
\hline Queima de ponteiros & Colletotrichum sp. & Eucalyptus viminalis, E. grandis, E. dunnii & $\mathrm{PR}, \mathrm{SC}$ & Maschio et al. (1996) \\
\hline Ferrugem & Puccinia psidii & Eucalyptus grandis, E. dunnii & $\begin{array}{l}\mathrm{PR}, \mathrm{SC} \\
\mathrm{RS}\end{array}$ & Auer et al. (2010) \\
\hline $\begin{array}{l}\text { Cancro por } \\
\text { Crysoporthe }\end{array}$ & Crysoporthe cubensis & $\begin{array}{l}\text { Eucalyptus dunnii, E. grandis, E. oreades, } \\
\text { E. viminalis }\end{array}$ & $\mathrm{PR}, \mathrm{SC}$ & Auer (1996) \\
\hline $\begin{array}{l}\text { Cancro por } \\
\text { Botryosphaeria }\end{array}$ & $\begin{array}{l}\text { Botryosphaeria dothidea - } \\
\text { Dothiorella } \mathrm{sp} .\end{array}$ & $\begin{array}{l}\text { Eucalyptus badjensis, E. benthamii, } \\
\text { E. globulus }\end{array}$ & PR, RS & Auer \& Santos (2009a) \\
\hline $\begin{array}{l}\text { Seca e morte de } \\
\text { árvores }\end{array}$ & Cytospora sp. & Eucalyptus viminalis & PR & Maschio et al. (1996) \\
\hline Cancro da haste & Phomopsis sp. & Eucalyptus dunnii & PR & Auer \& Santos $(2009 a$ \\
\hline Podridão do cerne & $\begin{array}{l}\text { Associação de vários grupos } \\
\text { de fungos decompositores de } \\
\text { madeira }\end{array}$ & $\begin{array}{l}\text { Eucalyptus dunnii, E. grandis, E. robusta, } \\
\text { E. saligna, E. urophylla }\end{array}$ & $\begin{array}{l}\mathrm{PR}, \mathrm{SC}, \\
\quad \mathrm{RS}\end{array}$ & Auer \& Santos (2009a) \\
\hline Seca de ponteiros & $\begin{array}{l}\text { Botryosphaeria rhodina - } \\
\text { Lasiodiplodia theobromae }\end{array}$ & C. citriodora, E. grandis & PR & Auer \& Santos (2009a) \\
\hline Murcha bacteriana & $\begin{array}{l}\text { Ralstonia solanacearum } \\
\text { biovar } 1\end{array}$ & $\begin{array}{l}\text { Eucalyptus urophylla, E. grandis, } \\
\text { E. urograndis }\end{array}$ & $\mathrm{SC}$ & Auer \& Santos (2009a) \\
\hline
\end{tabular}




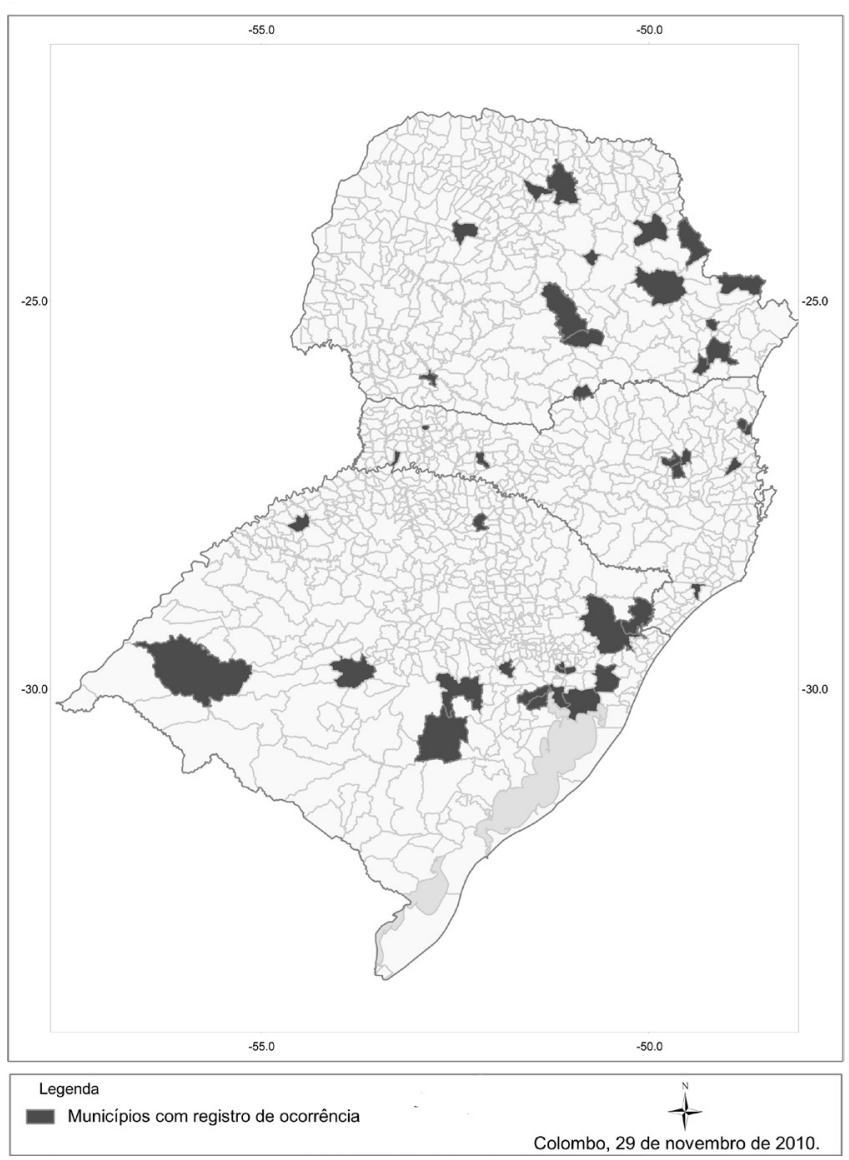

Figura 1. Distribuição da ferrugem em mirtáceas na região Sul do Brasil.

3) Manchas foliares por Cylindrocladium, Mycosphaerella e Teratosphaeria - a mancha de $C y l i n d r o c l a d i u m$ foi encontrada em $E$. dunnii, E. viminalis, E. grandis e E. urophylla. As manchas causadas por Mycosphaerella e Teratosphaeria foram registradas em E. dunnii, E. viminalis, E. saligna, E. globulus, E. grandis e E. camaldulensis (Ferreira, 1989; Alfenas et al., 2009, Pérez et al., 2009). Estes patógenos foliares causam a redução da área fotossintética e a estagnação do crescimento das árvores severamente atacadas, principalmente em árvores jovens. $\mathrm{O}$ impacto pode ser verificado na redução da produtividade nos estágios iniciais dos plantios e os prejuízos podem se estender até o final da rotação.

As doenças de viveiro, tais como a ferrugem do eucalipto e a mancha foliar de Cylindrocladium, causam impactos diretamente sobre a produção de mudas de eucalipto, afetando o fornecimento das mesmas para a formação de plantios e maciços florestais. Algumas doenças que ocorrem em viveiros, além de causar danos às plantas em seu estágio juvenil, podem atingir os plantios até o segundo ou terceiro ano de vida. De acordo com Alfenas et al. (2009), o ataque de Cylindrocladium candelabrum e de Rhizoctonia sp. reduziu o enraizamento de estacas de $55 \%$ para $10 \%$, enquanto que em minijardim clonal a céu aberto as perdas foram significativas a ponto de comprometer a produção anual de mudas e o cronograma de plantio. Tais surtos são esporádicos e associados com eventuais condições climáticas favoráveis, mas reforçam a necessidade do contínuo monitoramento das condições de produção de mudas nos viveiros florestais.

4) Podridão de cerne de árvores vivas - esta doença não possui um agente principal, podendo ser associada com um complexo de fungos decompositores de madeira. A doença foi registrada em E. grandis e E. dunnii, mas na literatura as espécies E. urophylla e E. camaldulensis são citadas como suscetíveis (Castro, 1982). Vale destacar que esta doença ocorre internamente sem apresentar sintomas externos, e somente diagnosticados quando as árvores são cortadas. O principal dano é o apodrecimento interno da madeira acarretando a redução no volume e na qualidade energética da madeira produzida, notadamente na porção interna da tora afetada pela doença (Foelkel et al., 1986).

5) Murcha bacteriana por Ralstonia - a doença é causada pela bactéria Ralstonia solanacearum biovar I e foi verificada na região Sul em árvores jovens de $E$. grandis, E. urophylla e no híbrido comercial urograndis (Auer \& Santos, 2009a). Segundo Alfenas et al. (2009), a murcha bacteriana ocorre em árvores com idade a partir dos quatro meses, provocando murcha e necrose na região da nervura central das folhas, bronzeamento e ou amarelecimento, com desfolha ascendente. No Brasil, esta doença foi registrada em culturas agronômicas, especialmente de tomate e batata, e pode ser considerada como relativamente recente para a eucaliptocultura (Alfenas et al., 2006). A doença teria sua primeira ocorrência no início da década de 1980, em plantios de E. grandis em Minas Gerais, depois no Pará, na Bahia, em plantios realizados em áreas recém-desmatadas e resultaram em até $25 \%$ de mortalidade (Robbs et 
al., 1988). Apesar da presença da bactéria no solo, o enovelamento das raízes das mudas e trincas na base da árvore causado pela excessiva temperatura do solo pode criar portas de entrada para a $R$. solanacearum (Alfenas et al., 2009). Assim, o dano principal é a mortalidade de árvores jovens, reduzindo o estande e a produtividade das florestas.

6) Mancha foliar bacteriana - esta doença tem sido associada a várias bactérias, contudo na região Sul foi constatada apenas Xanthomonas axonopodis (Auer et al., 2009a). A doença tem se espalhado pelos plantios de eucalipto e uma das principais vias de disseminação da doença é o uso de mudas infectadas. Ainda não se conhece ou se quantificou os prejuízos que esta doença pode causar em médio e longo prazos nos plantios de eucalipto.

Os plantios comerciais de eucalipto normalmente apresentam doenças causadas por fungos. Contudo, algumas enfermidades de origem bacteriana vêm sendo verificadas desde 2009 na parte aérea de mudas e árvores jovens de eucalipto no Brasil (Alfenas et al., 2009). Dentre estas doenças, destaca-se a mancha foliar causada pela bactéria $X$. axonopodis, que desperta preocupação pela facilidade com que é disseminada através de mudas infectadas. Esta doença ocorria apenas nas regiões brasileiras tradicionais da eucaliptocultura como Sudeste e Nordeste. Entretanto, com seu avanço para outras regiões, essa bacteriose já foi registrada nos estados de Santa Catarina, Paraná e, mais recentemente, no Mato Grosso (Auer \& Santos, 2009a), que fazem parte da expansão do eucalipto ocorrida na última década. Alfenas et al. (2009) comentaram sobre o registro dessa doença em mudas em viveiros na Argentina, e também na Bahia, Amapá, Espírito Santo, Minas Gerais, Pará, Rio Grande do Sul e São Paulo.

Outro aspecto interessante da bacteriose é o número elevado de espécies comerciais de eucalipto que ela infecta, pois já foi registrada em Eucalyptus cloeziana, $E$. grandis, E. globulus, E. maidenii, E. pellita, E. regnans, E. robusta, E. saligna, E. urophylla e E. viminalis (Alfenas et al., 2009). Também tem sido constatada em plantios com o híbrido urograndis (Auer \& Santos, 2009a). A estratégia de controle para uma doença desta natureza envolve a sanidade do viveiro, com a produção e expedição de mudas sadias para os plantios, de modo a impedir a disseminação das bactérias para os plantios jovens.
7) Problemas abióticos - podem causar redução significativa na produção de madeira para energia, devido à menor produtividade inicial das florestas, como resultado da mortalidade de árvores jovens. Esta mortalidade normalmente é decorrente da utilização de mudas impróprias para o plantio (com sistema radicular deformado, enovelado ou encachimbado) ou de práticas inadequadas para a implantação do povoamento florestal (Santos et al., 2008; Ferreira, 1989; Alfenas et al., 2009).

Outro problema abiótico a ser destacado é a ocorrência de geadas na região Sul do Brasil. A geada causa mortalidade de mudas recém-plantadas e árvores jovens no campo e a seca e morte de ponteiros dos indivíduos mais velhos (Santos et al., 2001). As espécies de eucalipto a serem plantadas devem ser escolhidas em função de sua resistência a este tipo de evento climático. $\mathrm{O} E$. benthamii é o principal indicado para áreas em que a geada ocorre com certa frequência e o $E$. dunnii em locais onde as geadas são fracas (Paludzyszyn Filho et al., 2006). Novos materiais estão sendo desenvolvidos para contornar o problema das geadas, mas necessitam ser testados a campo para confirmar sua resistência.

Com relação aos problemas de origem abiótica, destaca-se o plantio de mudas mantidas além do prazo ideal de permanência no viveiro, com desproporção entre a parte aérea e as raízes. Outro problema é que este tempo de permanência maior induz o enovelamento do sistema radicular ou ainda promove a fusão das raízes no orifício inferior do tubete. Tais tipos de deformação das raízes das mudas têm se agravado por falta de informação e treinamento dos viveiristas. Estas mudas com raízes deformadas condicionam alta mortalidade de árvores jovens de eucalipto. Outros problemas abióticos podem ocorrer quando o plantio é feito de forma inadequada, provocando deformação do sistema radicular e aumentando a mortalidade em plantações jovens (Santos et al., 2008).

É muito comum constatar a falta de treinamento e de experiência por parte dos plantadores de eucalipto, que poderia ser corrigida por meio de programas regionais de extensão rural ou florestal, para transferir os conhecimentos adequados à silvicultura correta.

As demais doenças listadas nas Tabelas 1 e 2 ocorrem de forma muito isolada e cujas informações seguras sobre os danos e riscos potenciais na produção e qualidade da madeira ainda não foram obtidas. Estas doenças causam danos somente na fase de produção de mudas. 


\section{Conclusões}

As doenças potencialmente importantes para a produção de madeira destinada à energia na região Sul do Brasil são: o cancro, a ferrugem, as manchas foliares causadas por Cylindrocladium e por Mycosphaerella/ Teratosphaeria, a murcha por Ralstonia e a podridão de cerne de árvores vivas. A existência de material genético resistente ainda continua sendo importante para o controle das doenças mencionadas, através da busca de genótipos resistentes dentro e fora da região Sul do País. Apesar da possibilidade de obtenção de clones, é recomendável que se busque a formação de populações e progênies resistentes de modo a garantir a variabilidade genética e dificultar o aparecimento de novas raças virulentas.

As doenças de campo são, sem dúvida, as que podem impactar negativamente a silvicultura do eucalipto quanto à sobrevivência e ao crescimento das árvores, com reflexos na produção de madeira, tanto no volume como na sua qualidade energética.

Também deve ser destacado o problema da alteração climática em cenários futuros para o Brasil, que concorrerá para o estressamento das plantas. Segundo Hamada et al. (2008), prevê-se uma redução da precipitação no Brasil e maiores períodos de estiagem, o que pode agravar a mortalidade de árvores jovens. De forma indireta, as alterações climáticas podem afetar o ciclo das relações patógeno-hospedeiro, aumentando a incidência e a severidade de algumas doenças florestais e impedindo outras (Furtado et al., 2008; Alfenas et al., 2009). A região Sul do Brasil que possui estações do ano mais definidas de verão e inverno pode ter algumas de suas áreas com climas alterados, o que permitiria a ocorrência de patógenos de clima tropical em espécies que normalmente não são hospedeiras. Um exemplo é o cancro do eucalipto, doença cujo agente causal é típico de regiões tropicais (Ferreira, 1989), mas pode ser encontrado em regiões mais frias do Brasil (Auer, 1996).

Por fim, é preocupante a entrada de patógenos exóticos na região Sul do Brasil (Auer \& Santos, 2009b), tendo como exemplo o fungo Teratosphaeria nubilosa (Pérez et al., 2009) e seus impactos em $E$. globulus. Esta possibilidade de novos patógenos criará demandas de pesquisa para medidas de mitigação, enquanto não forem desenvolvidos materiais genéticos resistentes. Existe uma série de patógenos exóticos em outras regiões do globo, notadamente nos centros de origem do eucalipto (Oceania), que depreciam suas florestas nativas e plantações de eucalipto. As informações sobre a distribuição e dispersão mundial, impactos na produtividade e espécies atacadas devem ser constantemente avaliadas pelos setores governamentais e produtivos para implantar medidas que impeçam sua entrada no Brasil.

\section{Referências}

ALFENAS, A. C.; ZAUZA, E. A. V.; MAFIA, R. G.; ASSIS, T. F. Clonagem e doenças do eucalipto. 2. ed. Viçosa, MG: UFV, 2009. 500 p.

ALFENAS, A. C.; MAFIA, R. G.; SARTÓRIO, R. C.; BINOTI, D. H. B.; SILVA, R. R.; LAU, D.; VANETTI, C. A. Ralstonia solanacearum em viveiros clonais de eucalipto no Brasil. Fitopatologia Brasileira, Brasília, DF, v. 31, p. 357-366, 2006.

AUER, C. G. A ocorrência do cancro do eucalipto no estado do Paraná e de Santa Catarina. Boletim de Pesquisa Florestal, Colombo, v. 32/33, p. 81-85, 1996.

AUER, C. G.; SANTOS, A. F. dos. Principais doenças em espécies de eucalipto utilizadas para a produção de energia na Região Sul do Brasil In: CONGRESSO BRASILEIRO SOBRE FLORESTAS ENERGÉTICAS, 1, 2009, Belo Horizonte. Anais... Colombo: Embrapa Florestas, 2009a. 1 CD-ROM. (Embrapa Florestas. Documentos, 178).

AUER, C. G.; SANTOS, A. F. dos. Reconhecimento e identificação dos principais patógenos de importância quarentenária associados a materiais de propagação ou madeira. Colombo: Embrapa Florestas, 2009b. 1 CD-ROM. (Embrapa Florestas. Documentos, 192).

AUER, C. G.; SANTOS, A. F. dos; BORA, K. C. A ferrugem do eucalipto na região Sul do Brasil. Colombo: Embrapa Florestas, 2010. 5 p. (Embrapa Florestas. Comunicado técnico, 252).

CASTRO, H. A. Podridão de cerne de árvores vivas de Eucalyptus na região de Guaiba, RS: ocorrência e etiologia. 1982. 58 f. Dissertação. (Mestrado em Agronomia) - Escola Superior de Agricultura “Luiz de Queiroz", Universidade de São Paulo, Piracicaba, SP.

FERREIRA, F. A. Patologia florestal: principais doenças florestais no Brasil. Viçosa, MG: SIF, 1989. 570 p.

FOELKEL, C. E. B.; BUSNARDO, C. A.; RECH, B. O fenômeno do apodrecimento central do cerne de árvores vivas de Eucalyptus: qualidade da madeira. IPEF, Piracicaba, SP, n. 33, p. 31-38, 1986.

FURTADO, E. L.; SANTOS, C. A. G.; MASSON, M. V. Impacto potencial das mudanças climáticas sobre a ferrugem do eucalipto. In: GHINI, R.; HAMADA, E. (Ed.). Mudanças climáticas: impactos sobre doenças de plantas no Brasil. Brasília, DF: Embrapa Informação Tecnológica; Jaguariúna: Embrapa Meio Ambiente, 2008. p. 274-286.

KRUGNER, T. L. Doenças do eucalipto: Eucalyptus spp. In: GALLI, F. (Coord.). Manual de fitopatologia. São Paulo: Agronômica Ceres, 1980. v. 2. p. 275-296. 
KRUGNER, T. L.; AUER, C. G. Doenças dos eucaliptos. In: KIMATI, H.; AMORIM, L.; REZENDE, J. A. M.; BERGAMIN FILHO, A.; CAMARGO, L. E. A. Manual de fitopatologia: doenças das plantas cultivadas. 4. ed. São Paulo: Agronômica Ceres, 2005. v. 2. p. 319-332.

HAMADA, E.; GONÇALVES, R. R. do; VALLE; ORSINI, J. A. M.; GHINI, R. Cenários climáticos futuros para o Brasil. In: GHINI, R.; HAMADA, E. (Ed.). Mudanças climáticas: impactos sobre doenças de plantas no Brasil. Brasília, DF: Embrapa Informação Tecnológica; Jaguariúna: Embrapa Meio Ambiente, 2008. p. 25-73.

MASCHIO, L. M. de A.; AUER, C. G.; GRIGOLETTI JUNIOR, A. Fungos associados a Eucalyptus spp. no Paraná e em Santa Catarina. Colombo: EMBRAPA-CNPF, 1996. 3 p. (EMBRAPACNPF. Pesquisa em andamento, 5).

MASSON, M. V. Ferrugem do eucalipto: planejamento evasivo, estimativa de dano e análise da viabilidade do controle químico. 2009. 167 f. Dissertação. (Mestrado em Agronomia) - Faculdade de Ciências Agronômicas, Universidade Estadual Paulista, Botucatu.

PALUDZYSZYN FILHO, E.; SANTOS, P. E. T. dos; FERREIRA, C. A. Eucaliptos indicados para plantio no Estado do Paraná. Colombo: Embrapa Florestas, 2006. 45 p. (Embrapa Florestas. Documentos, 129).
PÉREZ, G.; SLIPPERS, B.; WINGFIELD, B. D.; FINKENAUER, E.; WINGFIELD, M. J. Mycosphaerella leaf disease (MLD) outbreak on Eucalyptus globulus in Brazil caused by Teratosphaeria (Mycosphaerella) nubilosa. Phytopathologia Mediterranea, Roma, v. 48, n. 2, p. 302-306, 2009.

ROBBS, C. F.; CRUZ, A. P.; RODRIGUES NETO, J. Algumas estratégias de controle à murcha bacteriana (Pseudomonas solanacearum) em eucaliptos. Jaguariúna: EMBRAPA CNPDA, 1988. 4 p. (EMBRAPA CNPDA. Comunicado técnico, 3).

SANTOS, A. F. dos; AUER, C. G.; GRIGOLETI JUNIOR, A. Doenças do eucalipto no sul do Brasil: identificação e controle. Colombo: Embrapa Florestas, 2001. 20 p. (Embrapa Florestas. Circular técnica, 45).

SANTOS, A. F. dos; AUER, C. G. Controle químico da ferrugem do eucalipto em plantios jovens. Colombo: Embrapa Florestas, 2011. 3 p. (Embrapa Florestas. Comunicado técnico, 274).

SANTOS, A. F. dos; AUER, C. G.; DEDECEK, R. A.; SANTOS, P. E. T.; DAMIN, H. D. Morte de árvores resultante de práticas inadequadas durante a implantação florestal. Colombo: Embrapa Florestas, 2008. 6 p. (Embrapa Florestas. Circular técnica, 158). 
